\title{
The Treatment Outcome and Radiation-Induced Toxicity for Patients with Head and Neck Carcinoma in the IMRT Era: A Systematic Review with Dosimetric and Clinical Parameters
}

\author{
Vassilis Kouloulias, ${ }^{1}$ Stella Thalassinou, ${ }^{1}$ Kalliopi Platoni, ${ }^{1}$ Anna Zygogianni, ${ }^{2}$ \\ John Kouvaris, ${ }^{2}$ Christos Antypas, ${ }^{2}$ Efstathios Efstathopoulos, ${ }^{1}$ and Kelekis Nikolaos ${ }^{1}$ \\ ${ }^{1}$ Second Department of Radiology, Radiotherapy Unit, Attikon University Hospital, Medical School, Rimini 1, \\ Xaidari, 12462 Athens, Greece \\ ${ }^{2}$ First Department of Radiology, Radiotherapy Unit, Aretaieion University Hospital, Medical School, Vas. Sofias 76, \\ 11528 Athens, Greece
}

Correspondence should be addressed to Vassilis Kouloulias; vkouloul@ece.ntua.gr

Received 16 May 2013; Revised 8 August 2013; Accepted 22 August 2013

Academic Editor: Tsair-Fwu Lee

Copyright (C) 2013 Vassilis Kouloulias et al. This is an open access article distributed under the Creative Commons Attribution License, which permits unrestricted use, distribution, and reproduction in any medium, provided the original work is properly cited.

A descriptive analysis was made in terms of the related radiation induced acute and late mucositis and xerostomia along with survival and tumor control rates (significance level at 0.016 , bonferroni correction), for irradiation in head and neck carcinomas with either 2D Radiation Therapy (2DRT) and 3D conformal (3DCRT) or Intensity Modulated Radiation Therapy (IMRT). The mean score of grade > II xerostomia for IMRT versus 2-3D RT was $0.31 \pm 0.23$ and $0.56 \pm 0.23$, respectively (Mann Whitney, $P<0.001$ ). The parotid-dose for IMRT versus $2-3 \mathrm{D}$ RT was $29.56 \pm 5.45$ and $50.73 \pm 6.79$, respectively (Mann Whitney, $P=0.016$ ). The reported mean parotid-gland doses were significantly correlated with late xerostomia (spearman test, rho $=0.5013, P<0.001$ ). A trend was noted for the superiority of IMRT concerning the acute oral mucositis. The 3-year overall survival for either IMRT or 2-3DRT was $89.5 \%$ and $82.7 \%$, respectively ( $P=0.026$, Kruskal-Wallis test). The mean 3 -year locoregional control rate was $83.6 \%$ (range: 70-97\%) and 74.4 (range: 61-82\%), respectively ( $P=0.025$, Kruskal-Wallis). In conclusion, no significant differences in terms of locoregional control, overall survival and acute mucositis could be noted, while late xerostomia is definitely higher in 2-3D RT versus IMRT. Patients with head and neck carcinoma should be referred preferably to IMRT techniques.

\section{Introduction}

Over the last years, radiotherapy has played a significant role in the treatment of head and neck cancers. $74 \%$ of head and neck cancer patients need to undergo either definitive or postoperative radiation therapy [1]. The transition from two-dimensional conventional radiotherapy (2D-RT) to three-dimensional conformal radiotherapy (3D-CRT), in addition to further technological evolutions in the field of radiotherapy, led to the successful clinical implementation of intensity modulated radiation therapy (IMRT) which constitutes an evolution of 3D-CRT [2]. The IMRT has been employed in clinical practice since 1995 resulting in a great specimen of clinical results from patients undergone this specific technique of radiotherapy [3]. The IMRT technique gives the ability to create treatment fields with varying beam intensity by using inverse planning and iterative optimization algorithms [4]. The irradiation beam can be adjusted to the irregularly shaped target volumes with extremely high precision whilst reducing the radiation delivered to the surrounding healthy tissue and critical structures such as spinal cord, brain stem, parotid glands, eyes, optic nerves, chiasma, lacrimal glands, cochlea, and mandible in case of head and neck cancer [5-7]. The ability of delivering lower doses of radiation to normal tissue while maintaining or increasing the dose in the target volume makes IMRT the most appropriate treatment option compared to $2 \mathrm{D}-\mathrm{RT}$ and 3D-CRT [8-12]. 
Radiation therapy causes acute and late toxicities that affect various organs and functions. One of the most common acute toxicities that occurs as an injury of the mucosa of the head and neck area due to irradiation is mucositis. In the case of late toxicity, the most common characteristic is xerostomia where the considerable reduction of saliva leads to persistent dryness of mouth, oral discomfort, sore throat, dental decay, difficulty in speech, taste alteration, and impairment of chewing and swallowing functions which can lead to nutritional depletion and weight loss [13-16]. According to the published results, IMRT technique improves the toxicity profiles without compromising the efficacy [9, 12, 17-19]. The reduction of acute and late toxicities $[8,9,12,18,20-$ $22]$ in conjunction with comparable or superior treatment outcomes $[8-10,20,21,23]$ increases the necessity of IMRT technique for the treatment of head and neck carcinomas.

The objective of this study is to review the already published results and compare the efficacy and toxicity between patients treated with conventional RT techniques (2DRT and 3DCRT) and those treated with IMRT technique for head and neck carcinomas.

\section{Materials and Methods}

The literature was accessed through PubMed and Scopus (March 2000-January 2013), using the terms "radiation therapy," "head and neck cancer," "toxicity," "tumor control," and "survival." Additional papers were identified by cross-referencing bibliographies of retrieved articles. Tumor control and survival outcomes for head and neck cancers were collected from 38 studies while outcomes of acute and late toxicity were collected from 33 studies. As far as toxicity is concerned, two of the most common acute and late radiation-induced morbidity were included such as mucositis and xerostomia. The mean parotid-gland dose was also recorded as it contributes to radiation-induced xerostomia. The published results were categorized according to the radiation therapy technique which was used for the treatment of head and neck carcinomas in order to estimate the differences in clinical outcomes. The present review study focused mainly on hypopharyngeal, nasopharyngeal, and oropharyngeal tumors as well as on tumors of the larynx and the oral cavity. Furthermore, clinical outcomes for curative reirradiation were not included in the collected data.

2.1. Statistical Analysis. The analysis included a statistical correlation with spearman-rho nonparametric test between either the RT technique (IMRT versus 2-3D RT) or the mean parotid dose and the incidence of late xerostomia. For the analysis of the differences of the doses at the parotids and the mean score of xerostomia stratified by the RT technique, we used the Mann-Whitney test. The potential impact of RT technique to either survival or locoregional control rate was evaluated with the Kruskal-Wallis test. According to the bonferroni correction, the significance level was set at 0.016 . Due to the efficient number of data concerning the survival and locoregional control rate of the 3-year-followup, we decided to make the analysis for the 3 -year survival and locoregional rate. The statistical analysis was performed with the SPSS version 10 software (Chicago, IL, USA).

\section{Results}

According to the published data, the head and neck primary site was as follows: oropharynx $41 \%$, nasopharynx $37 \%$, oral cavity $6 \%$, larynx/hypopharynx $15 \%$, and other tumor site 1\%. Among the studies, 2582 out of 4587 patients (56\%) received concurrent chemotherapy. In terms of radiation therapy technique, IMRT was given to 3618 out of 4587 patients $(79 \%)$ and 2-3D RT was given to 969 out of 4587 patients (21\%). Definitive versus post-operative RT was given to 3953 out of 4587 (86\%) versus 633 out of 4587 (14\%) patients, respectively.

Published results on tumor control outcomes in terms of local control (LC), regional control (RC), and locoregional control (LRC) and also on survival outcomes in terms of overall survival (OS), distant metastasis-free survival (DMFS), and disease-free survival (DFS) are presented in Table 1. Relevant data are shown according to the patient sample, primary tumor site and stage, treatment intention, median followup, and the percentage of patients that received radiotherapy combined with chemotherapy. The treatment outcomes referred to head and neck cancer patients underwent radiotherapy either with conventional radiotherapy techniques or IMRT. Twenty five trials with available data were analysed in terms of overall survival and locoregional control rate. The mean 3-year overall survival for either IMRT or $2-3 \mathrm{D}$ RT was $89.5 \%$ (range: $64-100 \%$ ) and $82.7 \%(71-88 \%$ ), respectively. The mean 3-year locoregional control rate $83.6 \%$ (range: $70-97 \%$ ) and 74.4 (range: $61-82 \%$ ), respectively. The Kruskal-Wallis test revealed a significant $(P=0.026)$ correlation of overall survival with RT technique (IMRT either 2-3DRT), while there was also a significant impact of IMRT technique to locoregional rate $(P=0.025)$. However, according to the bonferroni correction, neither of the above correlations was finally significant. In Table 2, the reported acute and late toxicity rates for mucositis and xerostomia are listed according to the median followup, radiation therapy technique (IMRT or 2-3D RT), and the percentage of patients that received chemotherapy combined with radiotherapy. Few data were available for late mucositis and acute xerostomia concerning the evaluated relevant publications. In the same table, the mean parotid-gland dose is also presented in order to depict the correlation with patient-rated xerostomia. Relevant data with xerostomia grading score and dose deposited at the parotid gland were available in twenty published trials. As shown in Figure 1, the spearman-rho test showed that there was a significant correlation of late xerostomia and mean dose at the parotid gland (rho $=0.5013, P<0.001$ ). According to Figure 2, the mean score of xerostomia for IMRT versus 2-3D RT was $0.31 \pm 0.23$ and $0.56 \pm 0.23$, respectively (Mann Whitney, $P<0.001)$. The mean dose deposited in the parotid gland for IMRT versus 2-3DRT was $29.56 \pm 5.45$ and $50.73 \pm$ 6.79 , respectively (Mann Whitney, $P=0.016$ ). By analysing thirty five relevant publications with available data with acute 


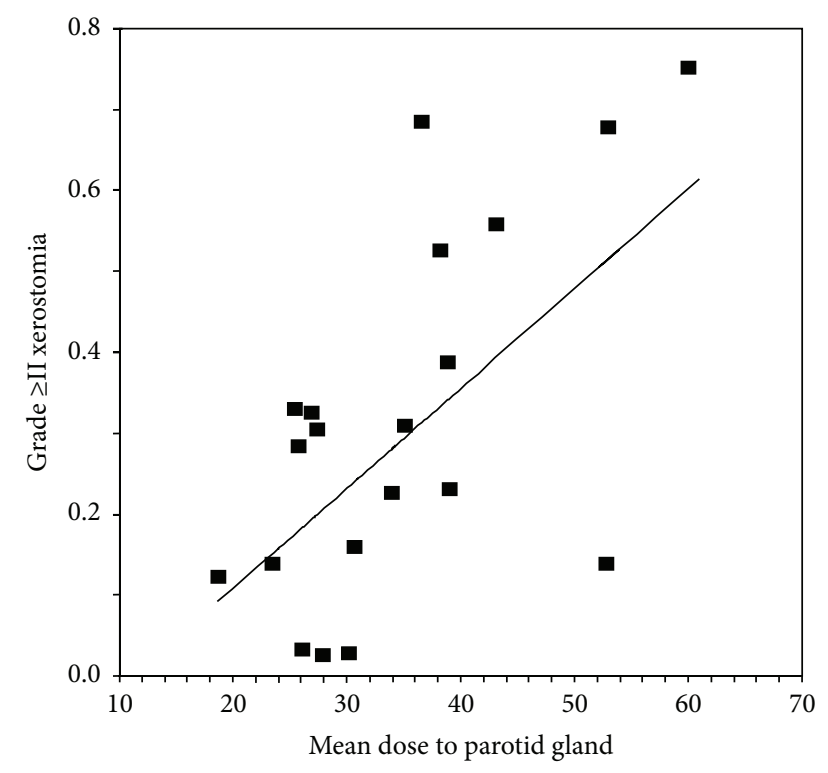

FIGURE 1: Linear curve estimation for grading $\geq$ II xerostomia related to the mean dose of parotid gland (rho $=0.5013, P<0.001$ ). The analysis was performed from 20 published trials with relevant available data.

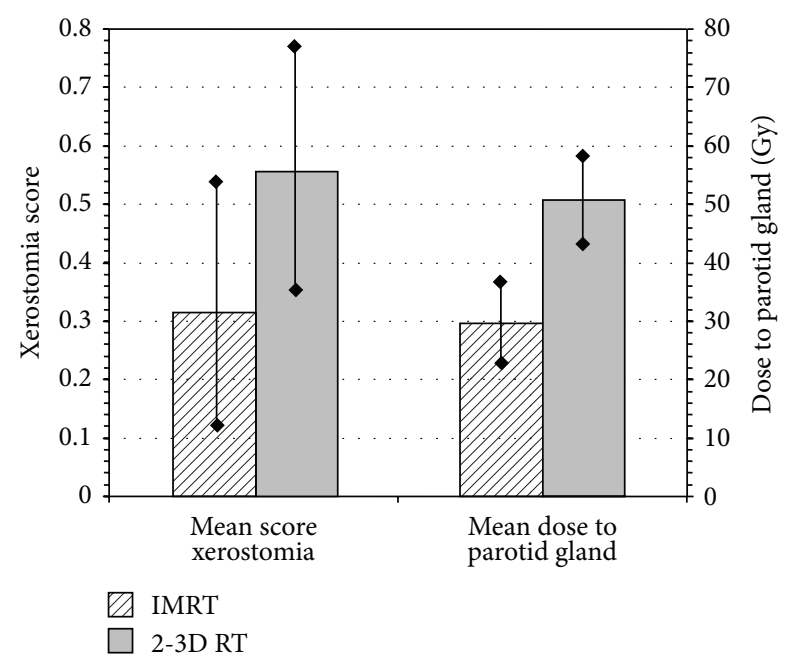

FIGURE 2: Comparative descriptive analysis of mean dose to parotids and mean xerostomia score stratified by RT technique. A significant difference was noted between the IMRT and conventional technique for both doses to parotids $(P=0.016)$ and xerostomia $(P<$ 0.001 ). The related scale referring to the $y$-axis either right or left is presenting the dose to the parotids and the xerostomia score, respectively. Data were available from twenty published trials.

mucositis, after comparing the mean values of acute mucositis stratified by IMRT versus 2-3DRT, we found a mean score of $0.71 \pm 0.23$ versus $0.89 \pm 0.07$ (Mann-Whitney test, $P=0.022$ ), respectively. However, according to bonferroni correction the difference was not significant.

At last, in Table 3 the range of tumor control and survival rates as well as the range of the acute and late toxicities rates (mucositis and xerostomia) is presented separately for each radiation therapy technique (IMRT versus 2-3D RT).

\section{Discussion}

With the increasing use of IMRT in head and neck carcinomas the improvement of treatment outcomes is the main concern. Several studies in the literature have reported favourable treatment outcomes for patients treated with IMRT technique $[8,9,24,25,28-30,32,34,37,41,45]$. Comparable rates of LRC are observed in Table 1 among the published studies for different radiotherapy techniques as also comparable survival rates. The comparable LRC and overall survival rates were also confirmed by the descriptive statistical analysis of this study where, beyond a trend in the superiority of IMRT, the differences between the IMRT and 2-3D RT were finally statistically insignificant. However, there are significant variations in tumor control and survival outcomes which are mainly caused by differences in patient sample, tumor stage, and followup among several studies. Chemotherapy also plays a significant role in the variation of clinical results. According to numerous studies, the combination of chemotherapy with radiotherapy improves the efficacy [55-58] at the cost of increased toxicity [55, 56]. In several studies, clinical results were divided according to patients treated with definitive radiotherapy and patients treated with postoperative radiotherapy. In the study of Chao et al. [27], combined surgery and postoperative IMRT lead to improved LRC and DFS compared with definitive IMRT in patients with oropharyngeal carcinoma. Similarly in the study of Studer et al. [48], LC of patients who received definitive IMRT for oral cavity cancer was substantially lower than the LC of patients who received postoperative IMRT.

The published clinical results demonstrate equivalence or noninferiority of IMRT in terms of tumor control or survival in any head and neck site [8-10, 20, 21, 23] while IMRT plays a significant role on the reduction of radiation-induced toxicity $[8,9,12,18,20-23]$. According to the published data as shown in Table 3, it seems that IMRT reduces late xerostomia down to $2.3 \%$. According to our descriptive analysis, the mean score of xerostomia was significantly lower in IMRT compared to conventional radiation therapy techniques (Mann Whitney, $P<0.001)$. The prevailing explanation for this inferior toxicity related to IMRT is that the preservation of salivary gland function itself has a protecting effect with regard to radiation-induced oral toxicity and secondary oral infections [59]. Although the data from Table 3 showed that IMRT technique can achieve a reduction of acute mucositis down to $32 \%$, our analysis showed only a trend for the superiority of IMRT.

The mean parotid-gland doses for patients treated with IMRT were significantly lower compared with the mean parotid-gland doses of patients treated with 2-3D RT (Mann Whitney, $P=0.016$ ). Furthermore, a significant correlation of late xerostomia and the mean parotid-gland dose was found (spearman test, rho $=0.5013, P<0.001$ ). Numerous studies have also reported significant correlation between the mean parotid dose and salivary flow after RT and the rate of 


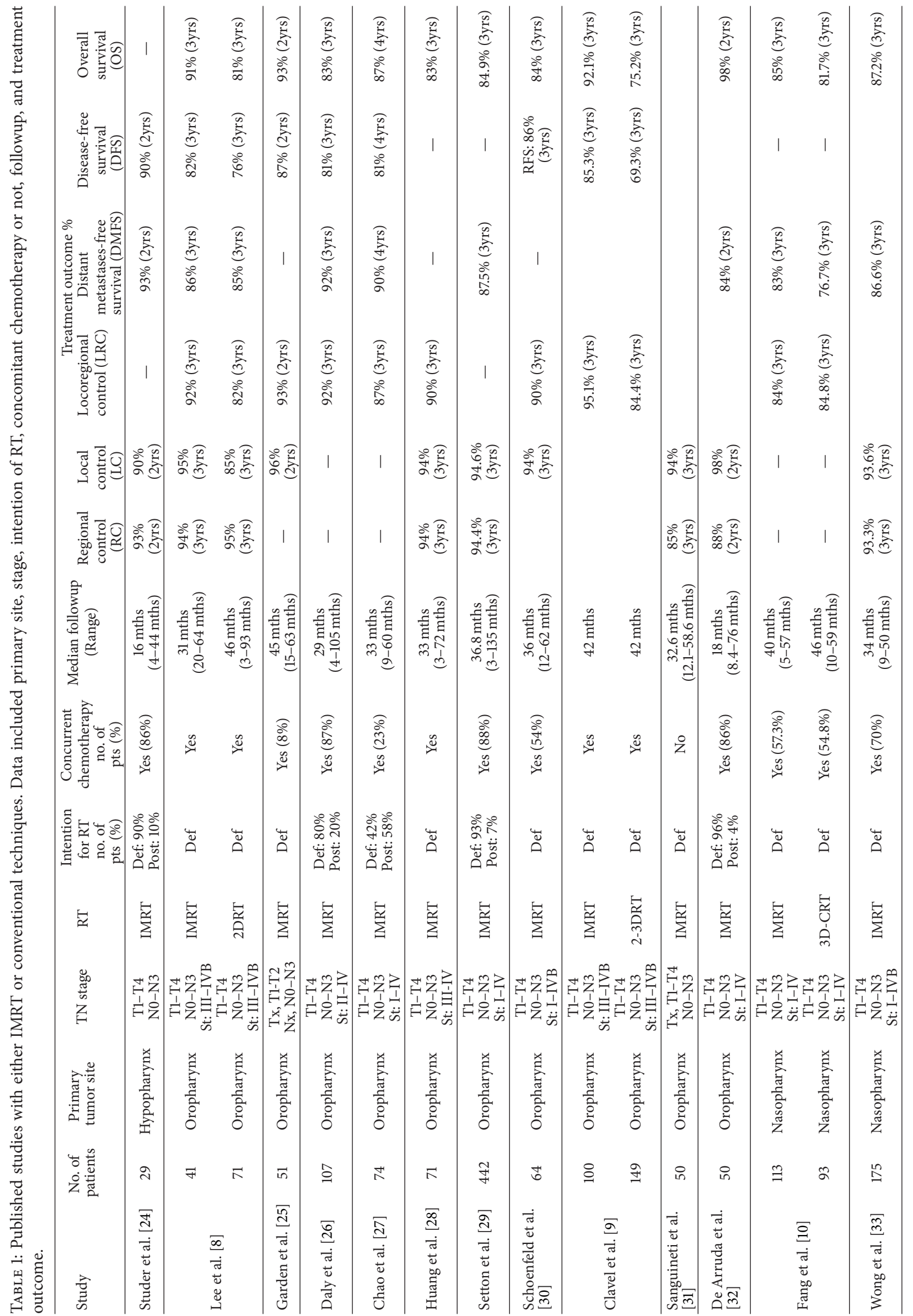




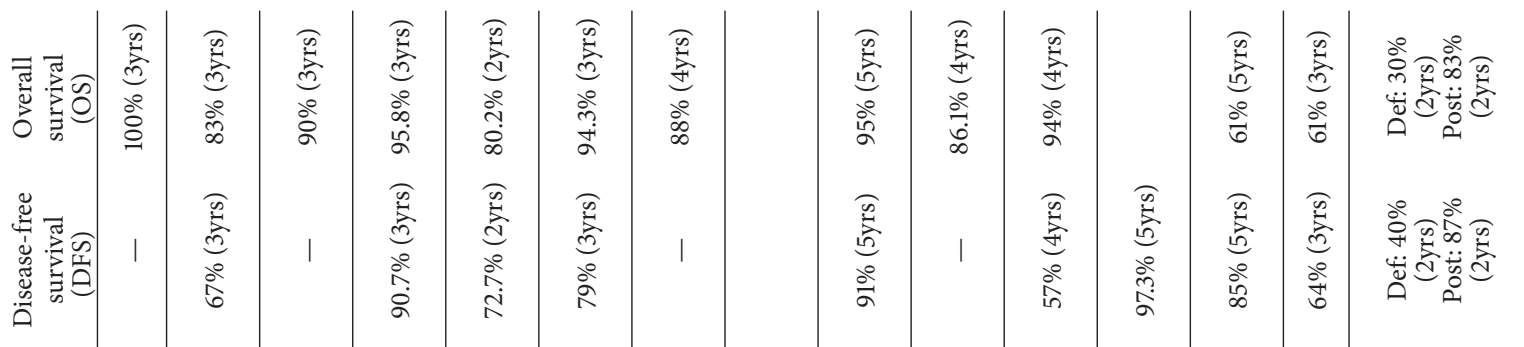

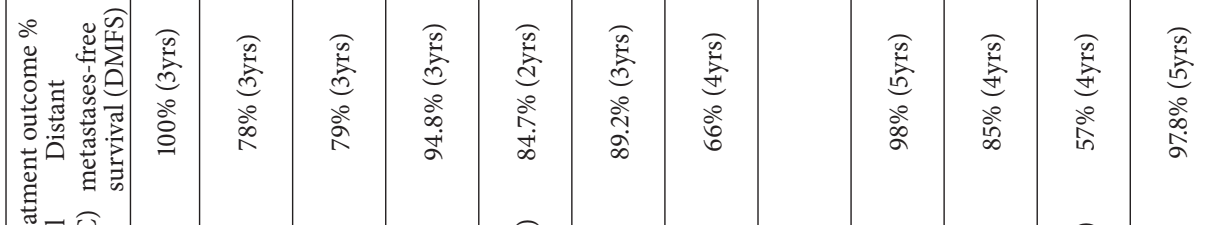

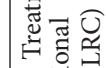

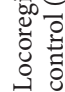

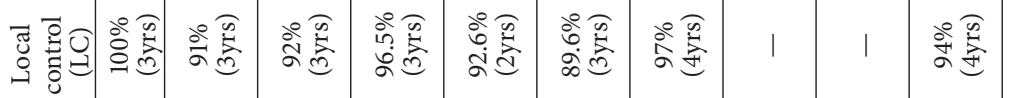

量总

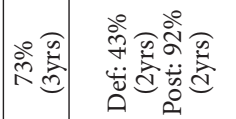

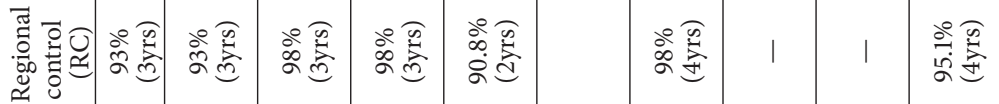

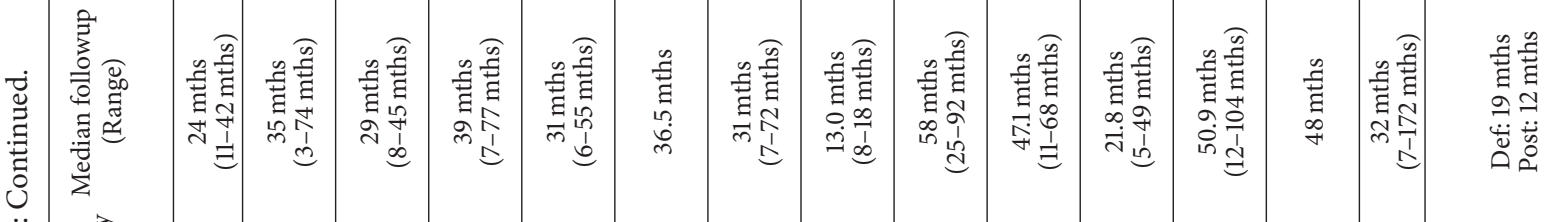

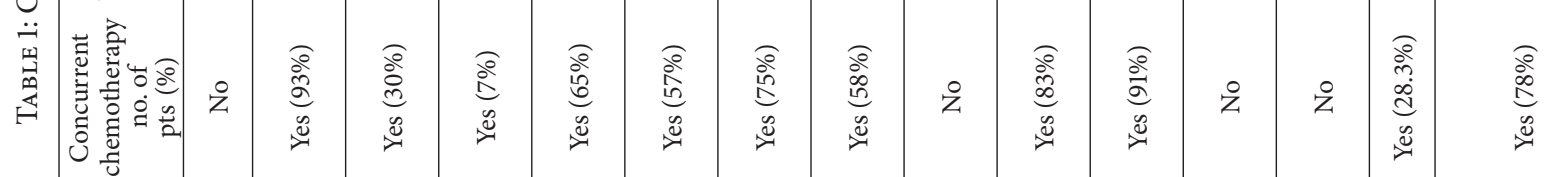

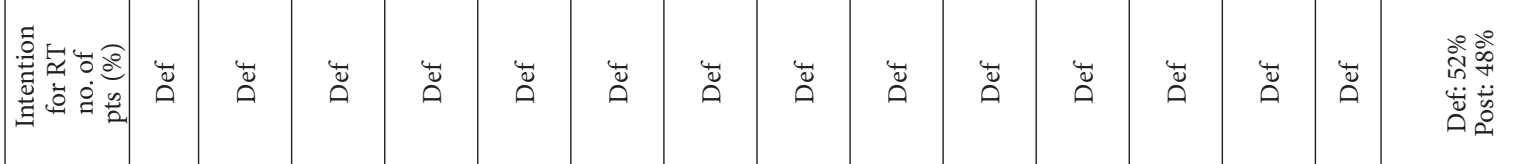

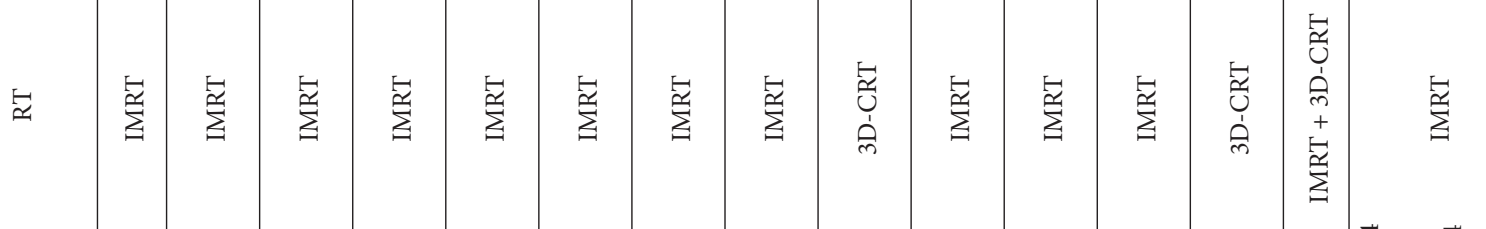

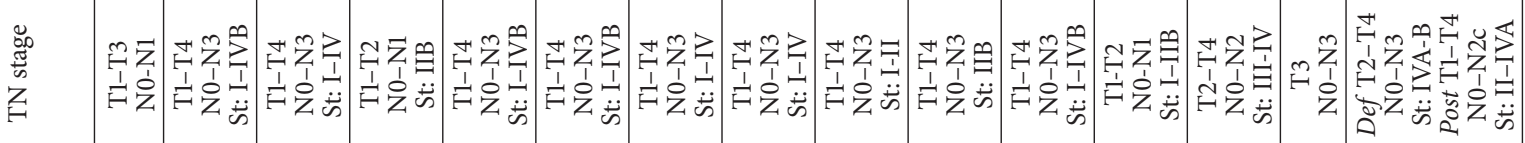

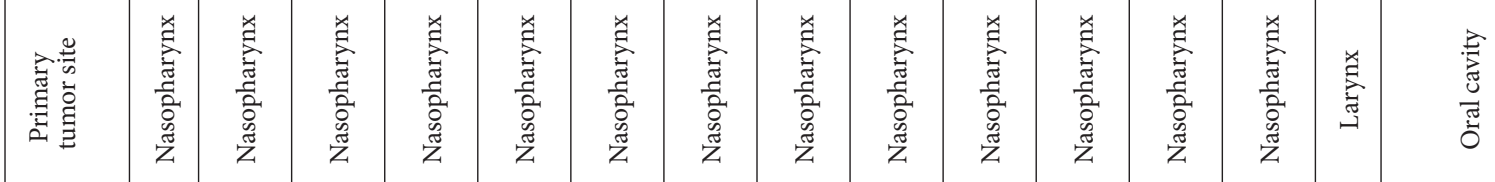

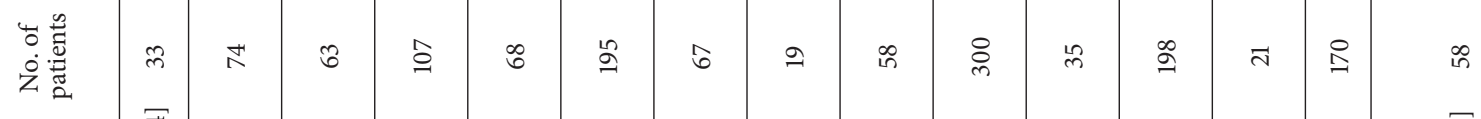

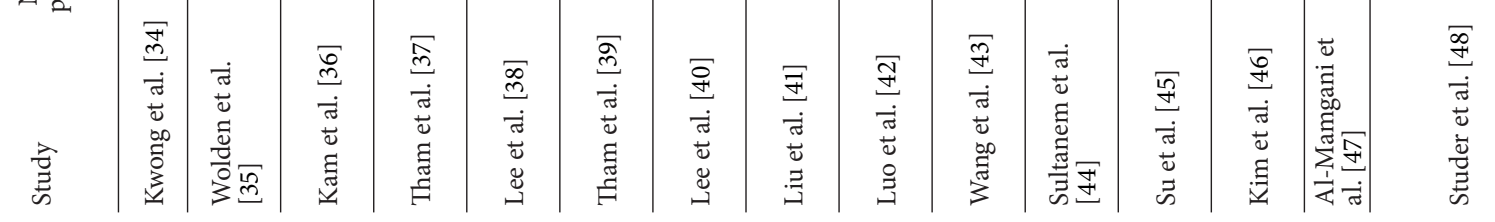




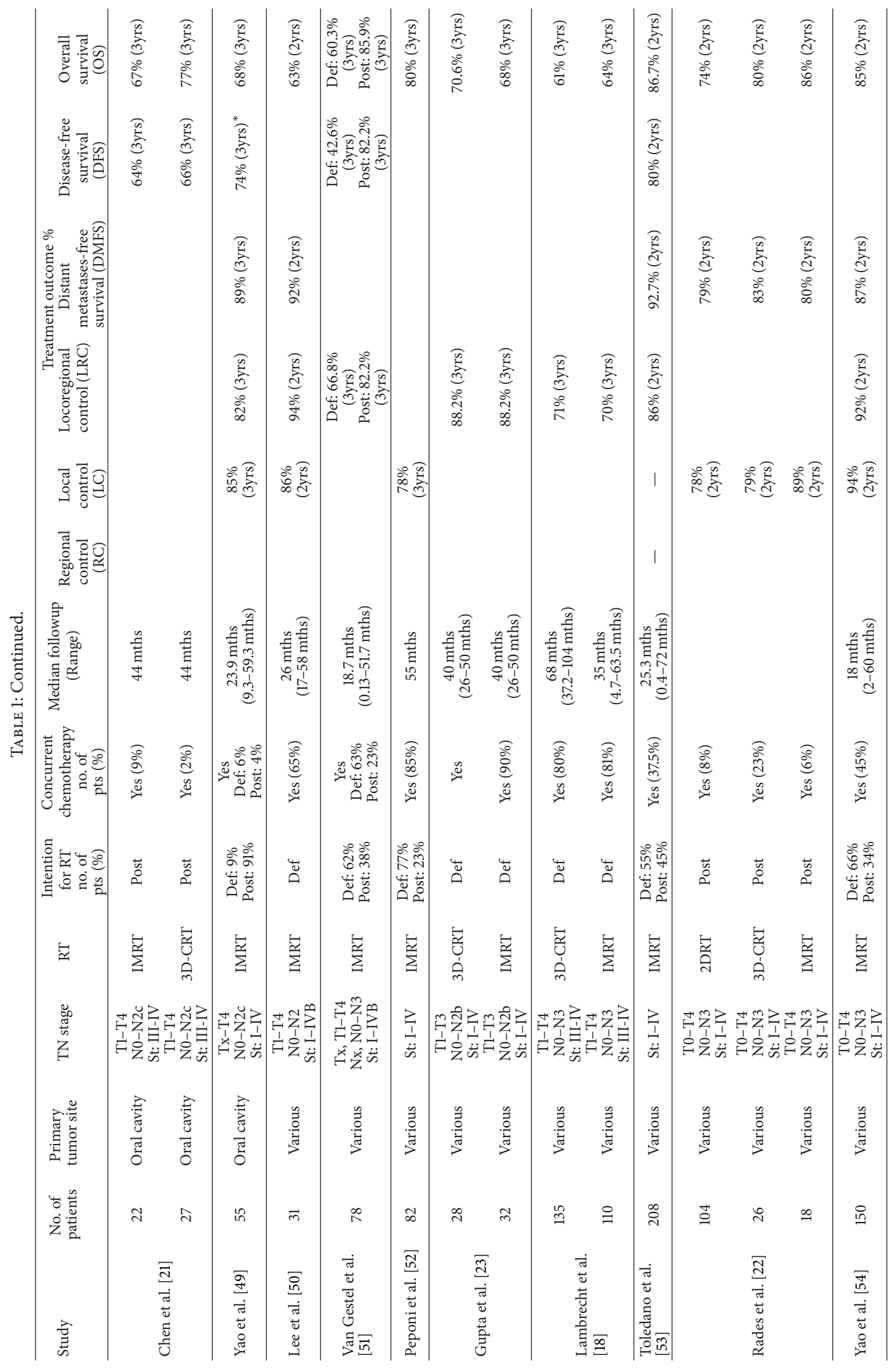


TABLE 2: Published studies with either IMRT or conventional techniques. Data included concomitant chemotherapy or not, follow-up, and radiation-induced toxicity.

\begin{tabular}{|c|c|c|c|c|c|c|c|c|}
\hline \multirow{3}{*}{ Study } & \multirow{3}{*}{$\begin{array}{l}\text { Radiation } \\
\text { treatment }\end{array}$} & \multirow{3}{*}{$\begin{array}{c}\text { Concurrent } \\
\text { chemotherapy } \\
\text { No. of patients (\%) }\end{array}$} & \multirow{3}{*}{$\begin{array}{l}\text { Median } \\
\text { followup (range) }\end{array}$} & \multicolumn{4}{|c|}{ Toxicity ( $\geq$ GrII) } & \multirow{3}{*}{$\begin{array}{l}\text { Mean parotid- } \\
\text { gland dose }\end{array}$} \\
\hline & & & & \multicolumn{2}{|c|}{ Mucositis } & \multicolumn{2}{|c|}{ Xerostomia } & \\
\hline & & & & Acute & Late & Acute & Late & \\
\hline Studer et al. $[24]^{\dagger}$ & IMRT & Yes $(86 \%)$ & 16 mths (4-44 mths) & $65 \%$ & - & - & - & \\
\hline \multirow{2}{*}{ Lee et al. [8] } & IMRT & Yes & 31 mths (20-64 mths) & $66 \%$ & - & $66 \%$ & $12 \%$ & \\
\hline & 2DRT & Yes & 46 mths (3-93 mths) & $72 \%$ & & $65 \%$ & $67 \%$ & \\
\hline Garden et al. [25] & IMRT & Yes $(8 \%)$ & 45 mths (15-63 mths) & - & - & - & - & $23.9 \mathrm{~Gy}$ \\
\hline Daly et al. $[26]^{\dagger}$ & IMRT & Yes $(87 \%)$ & $29 \mathrm{mths}$ (4-105 mths) & $93 \%$ & - & - & - & $33.2 \mathrm{~Gy}$ \\
\hline Chao et al. $[27]^{\dagger}$ & IMRT & Yes $(23 \%)$ & $33 \mathrm{mths}$ (9-60 mths) & $86 \%$ & - & - & $12 \%$ & $18.6 \mathrm{~Gy}$ \\
\hline Huang et al. [28] & IMRT & Yes & 33 mths (3-72 mths) & $92 \%$ & - & - & $34 \%$ & $25.5 \mathrm{~Gy}$ \\
\hline Setton et al. [29] ${ }^{\dagger}$ & IMRT & Yes $(88 \%)$ & 36.8 mths (3-135 mths) & $68 \%$ & - & $28 \%$ & $29 \%$ & $25.8 \mathrm{~Gy}$ \\
\hline Kwong et al. [34] & IMRT & No & 24 mths (11-42 mths) & $82 \%$ & - & - & $\begin{array}{l}40 \% \text { (1yrs) } \\
15 \% \text { (2yrs) }\end{array}$ & $38.8 \mathrm{~Gy}$ \\
\hline Wolden et al. [35] & IMRT & Yes $(93 \%)$ & 35 mths (3-74 mths) & & & & $32 \%$ (1yrs) & $35.2 \mathrm{~Gy}$ \\
\hline \multirow{2}{*}{ Kam et al. [36] } & IMRT & Yes $(30 \%)$ & 29 mths (8-45 mths) & $92 \%$ & & $75 \%$ & $23 \%(2 \mathrm{yrs})$ & 39 Gy \\
\hline & & & & & & & $16.7 \%(2 \mathrm{yrs})$ & $31 \mathrm{~Gy}$ \\
\hline Lee et al. [38] & IMRT & Yes $(65 \%)$ & 31 mths (6-55 mths) & - & $22 \%$ & - & $33 \%$ & \\
\hline Lee et al. [40] & IMRT & Yes $(75 \%)$ & 31 mths (7-72 mths) & $94 \%$ & - & & $58 \%$ & \\
\hline Liu et al. [41] & IMRT & Yes $(58 \%)$ & $13.0 \mathrm{mths}$ (8-18 mths) & - & $79 \%$ & - & $53 \%$ & $37.8 \mathrm{~Gy}$ \\
\hline Luo et al. [42] & 3D-CRT & No & 58 mths (25-92 mths) & $74 \%$ & $12 \%$ & & $12 \%$ & $52.8 \mathrm{~Gy}$ \\
\hline $\begin{array}{l}\text { Al-Mamgani } \\
\text { et al. [47] }\end{array}$ & $\begin{array}{l}\mathrm{IMRT}+ \\
\text { 3D-CRT }\end{array}$ & $\operatorname{Yes}(28.3 \%)$ & 32 mths (7-172 mths) & & & & $14.1 \%$ & 23.6 Gy \\
\hline Lee et al. [50] & IMRT & Yes $(65 \%)$ & 26 mths (17-58 mths) & $48 \%$ & & & $3.2 \%$ & $26 \mathrm{~Gy}$ \\
\hline $\begin{array}{l}\text { Van Gestel et al. } \\
{[51]^{\dagger}}\end{array}$ & IMRT & $\begin{array}{c}\text { Yes } \\
\text { Def: } 63 \% \\
\text { Post: } 23 \%\end{array}$ & 18.7 mths (0.13-51.7 mths) & $100 \%$ & & & $44 \%$ & \\
\hline Peponi et al. $[52]^{\dagger}$ & IMRT & Yes $(85 \%)$ & $55 \mathrm{mths}$ & & & & $\begin{array}{l}\text { Obj: } 7.3 \% \\
\text { Sub: } 3.6 \%\end{array}$ & \\
\hline \multirow{2}{*}{ Gupta et al. [23] } & 3D-CRT & Yes & 40 mths (26-50 mths) & $93 \%$ & & & & 53 Gy \\
\hline & IMRT & Yes $(90 \%)$ & 40 mths (26-50 mths) & $77 \%$ & & & & $34.3 \mathrm{~Gy}$ \\
\hline \multirow{2}{*}{$\begin{array}{l}\text { Lambrecht et al. } \\
\text { [18] }\end{array}$} & 3D-CRT & Yes $(80 \%)$ & 68 mths (37.2-104 mths) & $44 \%$ & & & $68 \%$ & 53 Gy \\
\hline & IMRT & Yes $(81 \%)$ & $35 \mathrm{mths}$ (4.7-63.5 mths) & $32 \%$ & & & $23 \%$ & $34 \mathrm{~Gy}$ \\
\hline $\begin{array}{l}\text { Toledano et al. } \\
{[53]^{\dagger}}\end{array}$ & IMRT & Yes $(37.5 \%)$ & $25.3 \mathrm{mths}$ (0.4-72 mths) & $\sim 73 \%$ & - & - & $\sim 58 \%$ & \\
\hline \multirow{2}{*}{ Clavel et al. [9] } & IMRT & Yes & $42 \mathrm{mths}$ & $75 \%$ & & & $8 \%(2 \mathrm{yrs})$ & \\
\hline & 2-3DRT & Yes & $42 \mathrm{mths}$ & $77 \%$ & & & $74 \%$ (2yrs) & \\
\hline \multirow{2}{*}{ Vergeer et al. $[20]^{\dagger}$} & IMRT & Yes $(43 \%)$ & - & & & & $32 \%$ (6 mths) & $27 \mathrm{~Gy}$ \\
\hline & 3D-CRT & Yes $(35 \%)$ & - & & & & $56 \%$ (6 mths) & $43 \mathrm{~Gy}$ \\
\hline \multirow{2}{*}{ Chen et al. [21] ${ }^{*}$} & IMRT & Yes $(9 \%)$ & $44 \mathrm{mths}$ & $87 \%$ & & & $36 \%$ & \\
\hline & 3D-CRT & Yes $(2 \%)$ & 44 mths & $89 \%$ & & & $82 \%$ & \\
\hline \multirow{2}{*}{ Nutting et al. [12] $]^{\dagger}$} & IMRT & Yes $(43 \%)$ & $44 \mathrm{mths}$ & $93 \%$ & & $71 \%$ & $69 \%$ & $36.5 \mathrm{~Gy}$ \\
\hline & 3D-CRT & Yes $(40 \%)$ & $44 \mathrm{mths}$ & $94 \%$ & & $91 \%$ & $76 \%$ & $61 \mathrm{~Gy}$ \\
\hline Wong et al. [33] & IMRT & Yes $(70 \%)$ & 34 mths (9-50 mths) & $67.4 \%$ & & & $2.3 \%$ & $30 \mathrm{~Gy}$ \\
\hline $\begin{array}{l}\text { Sultanem et al. } \\
{[44]}\end{array}$ & IMRT & Yes $(91 \%)$ & $21.8 \mathrm{mths}(5-49 \mathrm{mths})$ & $97 \%$ & & & $28 \%$ & \\
\hline Su et al. [45] & IMRT & No & 50.9 mths (12-104 mths) & $73 \%$ & & $36 \%$ & $\begin{array}{c}15.4 \% \text { (1yrs) } \\
9.0 \%(2 \mathrm{yrs})\end{array}$ & $31 \mathrm{~Gy}$ \\
\hline Wang et al. [43] & IMRT & Yes $(83 \%)$ & $47.1 \mathrm{mths}$ (11-68 mths) & $33.3 \%$ & & $4.7 \%$ & $12.3 \%(2 \mathrm{yrs})$ & $27.6 \mathrm{~Gy}$ \\
\hline
\end{tabular}


TABLE 2: Continued.

\begin{tabular}{|c|c|c|c|c|c|c|c|c|}
\hline \multirow{3}{*}{ Study } & \multirow{3}{*}{$\begin{array}{l}\text { Radiation } \\
\text { treatment }\end{array}$} & \multirow{3}{*}{$\begin{array}{c}\text { Concurrent } \\
\text { chemotherapy } \\
\text { No. of patients (\%) }\end{array}$} & \multirow{3}{*}{$\begin{array}{c}\text { Median } \\
\text { followup (range) }\end{array}$} & \multicolumn{4}{|c|}{ Toxicity ( $\geq$ GrII) } & \multirow{3}{*}{$\begin{array}{l}\text { Mean parotid- } \\
\text { gland dose }\end{array}$} \\
\hline & & & & \multicolumn{2}{|c|}{ Mucositis } & \multicolumn{2}{|c|}{ Xerostomia } & \\
\hline & & & & Acute & Late & Acute & Late & \\
\hline \multirow{3}{*}{ Rades et al. [22] ${ }^{*}$} & 2DRT & Yes $(8 \%)$ & & $\sim 90 \%$ & & & $73 \%$ & \\
\hline & 3D-CRT & Yes $(23 \%)$ & & $\sim 90 \%$ & & & $63 \%$ & \\
\hline & IMRT & Yes $(6 \%)$ & & $\sim 90 \%$ & & & $17 \%$ & \\
\hline \multirow{2}{*}{ Tham et al. [39] } & IMRT & Yes & $36.5 \mathrm{mths}$ & $29 \%(\mathrm{Gr} 3)$ & & $3 \%(\mathrm{Gr} 3)$ & & \\
\hline & IMRT & No & $36.5 \mathrm{mths}$ & $20 \%(\mathrm{Gr} 3)$ & & & & \\
\hline Kim et al. [46] & 3D-CRT & No & $48 \mathrm{mths}$ & $57 \%$ & & & $19 \%$ & \\
\hline $\begin{array}{l}\text { De Arruda et al. } \\
{[32]^{\dagger}}\end{array}$ & IMRT & Yes $(86 \%)$ & $18 \mathrm{mths}$ (8.4-76 mths) & $92 \%$ & & $60 \%$ & $33 \%$ & $26.5 \mathrm{~Gy}$ \\
\hline
\end{tabular}

${ }^{*}$ Postoperative RT; ${ }^{\dagger}$ definitive and postoperative RT; all the rest: definitive RT.

TABLE 3: Synoptic table with ranges of treatment outcome and toxicity between IMRT versus conventional techniques.

\begin{tabular}{|c|c|c|c|c|c|c|}
\hline \multirow{2}{*}{ RT } & \multicolumn{6}{|c|}{ Treatment outcome } \\
\hline & $\mathrm{RC}$ & $\mathrm{LC}$ & LRC & DMFS & DFS & OS \\
\hline IMRT & $85 \%-98 \%$ & $78 \%-100 \%$ & $70 \%-100 \%$ & $57 \%-100 \%$ & $57 \%-97.3 \%$ & $63 \%-100 \%$ \\
\hline \multirow[t]{3}{*}{ 2DRT-3DCRT } & $95 \%{ }^{*}$ & $78 \%-85 \%$ & $71 \%-93 \%$ & $76.7 \%-98 \%$ & $66 \%-91 \%$ & $61 \%-95 \%$ \\
\hline & \multicolumn{3}{|c|}{ Acute toxicity } & \multicolumn{3}{|c|}{ Late toxicity } \\
\hline & Mucositis & \multicolumn{2}{|c|}{ Xerostomia } & Mucositis & \multicolumn{2}{|c|}{ Xerostomia } \\
\hline IMRT & $32 \%-100 \%$ & \multicolumn{2}{|c|}{$4.7 \%-75 \%$} & $22 \%-79 \%$ & \multicolumn{2}{|c|}{$2.3 \%-69 \%$} \\
\hline 2DRT-3DCRT & $44 \%-94 \%$ & \multicolumn{2}{|c|}{$65 \%-91 \%$} & $12 \%{ }^{*}$ & \multicolumn{2}{|c|}{$12 \%-82 \%$} \\
\hline
\end{tabular}

${ }^{*}$ Available data from one study only.

patients suffer from xerostomia [17, 60-66]. A typical IMRT plan with parotid sparing technique for oral cavity carcinoma is shown in Figure 3. Furthermore, the direct comparison of dose volume histogram (DVH) for the right and left parotid gland between IMRT and 3DCRT is presented in Figure 4 . The results clearly demonstrate the superiority of IMRT technique in terms of toxicity, mainly due to parotidgland sparing.

In the literature, comparative studies showed differences regarding tumor control and toxicity profiles among the different radiotherapy techniques (IMRT versus 2-3D RT). In a recent study, Clavel et al. [9] reported superior outcomes (OS, DFS, and LRC) for IMRT patients treated with SIB compared to those treated with conventional radiation therapy techniques for locally advanced oropharyngeal cancer. On the other hand, the majority of the comparative studies demonstrate the equivalence of IMRT with the conventional radiation therapy techniques in regard to tumor control and survival for head and neck cancers [8, 10, 21-23]. In the study of Lee et al. [8], comparable treatment outcomes were observed for IMRT patients and patients treated with $2 \mathrm{D}$ conventional radiation therapy technique (2DRT) for locally advanced oropharyngeal carcinoma. Local control and survival appeared slightly superior for IMRT patients compared to 2DRT patients but this difference was statistically insignificant. Similar findings arising for head and neck cancers from the comparison between IMRT and 3DCRT confirm the equivalence in treatment outcomes of IMRT

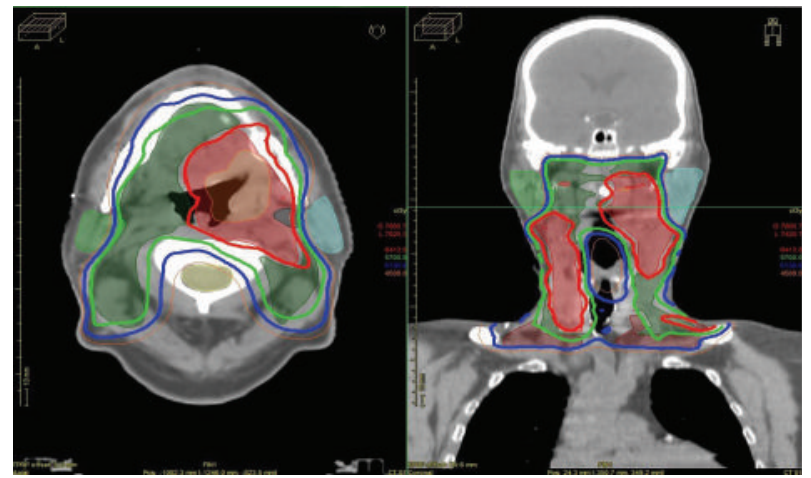

FIGURe 3: A typical IMRT plan with the parotid sparing technique for a carcinoma of the oral cavity. Three PTVs were contouring: primary site and all relevant lymph nodes as PTV1; primary site and clinical involved lymph nodes as PTV2; primary site only as PTV3. The technique used was integrated boost by means of 30 fractions with 1.8 Gy, $2 \mathrm{~Gy}$, and 2.25 Gy per fraction by PTV1, PTV2, and PTV3, respectively (ONCENTRA, treatment planning). The isodoses shown are the $95 \%$ of the prescribed doses per PTV: $45 \%$ in orange; $51.3 \%$ in blue; $57 \%$ in green; $64,13 \%$ in red (personal archive).

with conventional radiation therapy techniques $[10,18,21$, 23]. Rades et al. [22] compared treatments outcomes among IMRT, 3DCRT, and 2DRT for head and neck cancer patients treated with surgery followed by RT. Locoregional control 


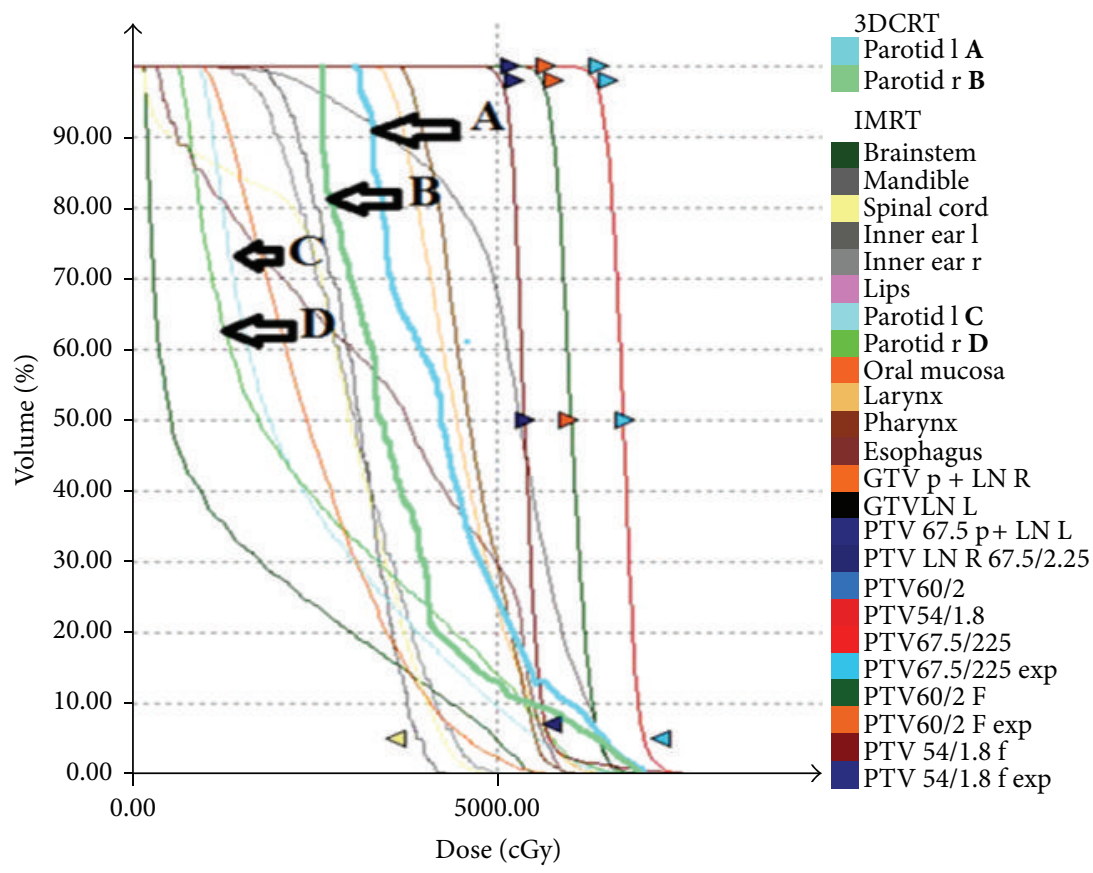

FIGURE 4: Comparison of the right and left parotid-gland DVHs of the same head and neck cancer patient (tumor site: oral cavity) for IMRT versus 3DCRT (3-dimensional conformal radiotherapy) technique. The arrows show the relevant DVHs for left and right parotid glands. A and $\mathbf{B}$ DVHs for parotids are shifted to the left (C and D) with IMRT techniques resulting in lower doses in the parotid glands (personal archive).

was similar for the three radiation techniques with IMRT being slightly superior.

As far as late toxicity is concerned, comparative studies report differences between IMRT and conventional RT techniques regarding patient-rated xerostomia $[8,9,12$, 18, 20-23]. Specifically, they demonstrate significantly less xerostomia for head and neck cancer patients treated with IMRT technique than for those treated with conventional radiotherapy techniques. In the studies of Lee et al. [8] and Lambrecht et al. [18], similar results of moderate to severe late xerostomia were observed (12\% versus $67 \%$ and $23 \%$ versus $68 \%$ for IMRT and Conv RT, resp.). Clavel et al. [9] reported significant lower xerostomia for IMRT patients compared to those receiveing conventional radiotherapy techniques for locally advanced oropharyngeal carcinoma (IMRT versus conventional RT: $8 \%, 74 \%$, resp.). Similarly in the study of Rades et al. [22], IMRT is associated with less xerostomia than $2-3$ D RT for head and neck cancers (17\% versus $63 \%$ and $73 \%)$. Regarding acute toxicity, rates of mucositis for IMRT and conventional RT were reported in several studies $[8,9,18$, $20,22,23]$. There are studies that demonstrate that patients receiving IMRT had acute toxicity comparable with those receiving 2-3D RT $[8,9,21-23]$ while other studies reported that more head and neck cancer patients treated with conventional radiation therapy techniques suffered from acute mucositis compared to those treated with $\operatorname{IMRT}[18,20]$.

In the case that our main concern is the reduction of xerostomia, then IMRT is the appropriate treatment option for head and neck cancer patients. However, when the main aspect is the tumor control or survival, we have to mention the lack of any randomized data to support a recommendation of IMRT over the conventional irradiation beam techniques in any head and neck site. Moreover, in our descriptive analysis, although there was a trend of better treatment outcome in favor of IMRT technique, no significant superiority was noted in terms of either overall survival or locoregional control rate. Definitely, a prospective randomized study comparing the two techniques stands in need.

\section{Conclusion}

The main conclusion of this study is that IMRT reduces late xerostomia compared with conventional three-dimensional conformal radiotherapy (3D-CRT) and conventional twodimensional radiotherapy (2DRT). The trend of superiority of IMRT regarding the acute mucositis as well as the overall survival and the locoregional control should be mentioned. However, there is an absence of a clear statistical superiority of IMRT for the various tumor sites as far as tumor control and survival are concerned. A prospective randomized study exploring the potential clinical impact (treatment outcome and radiation-induced toxicity) of IMRT versus 2-3D RT stands in need in order to extract safe conclusions about the definitive superiority of IMRT for tumor control as well as for radiation morbidity. In a parallel way, a meta-analysis with raw data from all relevant publications might also give more definite results in terms of the final potential impact of IMRT for either survival or acute oral mucositis. However, the trend 
of better treatment outcome in favor of IMRT deriving from our analysis should not be underestimated.

\section{Conflict of Interests}

The authors declare that they have no conflict if interests.

\section{References}

[1] G. Delaney, S. Jacob, and M. Barton, "Estimating the optimal radiotherapy utilization for carcinoma of the central nervous system, thyroid carcinoma, and carcinoma of unknown primary origin from evidence-based clinical guidelines," Cancer, vol. 106, no. 2, pp. 453-465, 2006.

[2] International Atomic Energy Agency, "Transition from 2D Radiotherapy to 3-D Conformal and Intensity Modulated Radiotherapy,' Tech. Rep. IAEA-TEC-DOC-1588, IAEA, Vienna, Austria, 2008.

[3] M. Bucci, P. Xia, N. Lee et al., "Intensity modulated radiation therapy for carcinoma of the nasopharynx: an update of the UCSF experience," International Journal of Radiation Oncology, Biology, Physics, vol. 60, pp. S317-S318, 2004.

[4] G. A. Ezzell, J. M. Galvin, D. Low et al., "Guidance document on delivery, treatment planning, and clinical implementation of IMRT: report of the IMRT subcommittee of the AAPM radiation therapy committee," Medical Physics, vol. 30, no. 8, pp. 2089-2115, 2003.

[5] C. Nutting, D. P. Dearnaley, and S. Webb, "Intensity modulated radiation therapy: a clinical review," British Journal of Radiology, vol. 73, no. 869, pp. 459-469, 2000.

[6] A. Eisbruch, "Intensity-modulated radiation therapy: a clinical perspective," Seminars in Radiation Oncology, vol. 12, no. 3, pp. 197-198, 2002.

[7] C.-S. Chui and S. V. Spirou, "Inverse planning algorithms for external beam radiation therapy," Medical Dosimetry, vol. 26, no. 2, pp. 189-197, 2001.

[8] N. Y. Lee, F. F. de Arruda, D. R. Puri et al., "A comparison of intensity-modulated radiation therapy and concomitant boost radiotherapy in the setting of concurrent chemotherapy for locally advanced oropharyngeal carcinoma," International Journal of Radiation Oncology. Biology. Physics, vol. 66, no. 4, pp. 966-974, 2006.

[9] S. Clavel, D. H. A. Nguyen, B. Fortin et al., "Simultaneous integrated boost using intensity-modulated radiotherapy compared with conventional radiotherapy in patients treated with concurrent carboplatin and 5-fluorouracil for locally advanced oropharyngeal carcinoma," International Journal of Radiation Oncology. Biology. Physics, vol. 82, no. 2, pp. 582-589, 2012.

[10] F.-M. Fang, C.-Y. Chien, W.-L. Tsai et al., "Quality of life and survival outcome for patients with nasopharyngeal carcinoma receiving three-dimensional conformal radiotherapy versus intensity-modulated radiotherapy - a longitudinal study," International Journal of Radiation Oncology. Biology. Physics, vol. 72, no. 2, pp. 356-364, 2008.

[11] A. M. Chen, B.-Q. Li, R. L. S. Jennelle et al., "Late esophageal toxicity after radiation therapy for head and neck cancer," Head and Neck, vol. 32, no. 2, pp. 178-183, 2010.

[12] C. M. Nutting, J. P. Morden, K. J. Harrington et al., "Parotidsparing intensity modulated versus conventional radiotherapy in head and neck cancer (PARSPORT): a phase 3 multicentre randomised controlled trial," The Lancet Oncology, vol. 12, no. 2, pp. 127-136, 2011.
[13] J. A. Langendijk, P. Doornaert, I. M. Verdonck-de Leeuw, C. R. Leemans, N. K. Aaronson, and B. J. Slotman, "Impact of late treatment-related toxicity on quality of life among patients with head and neck cancer treated with radiotherapy," Journal of Clinical Oncology, vol. 26, no. 22, pp. 3770-3776, 2008.

[14] A. De Graeff, J. R. J. De Leeuw, W. J. G. Ros, G. J. Hordijk, G. H. Blijham, and J. A. M. Winnubst, "A prospective study on quality of life of patients with cancer of the oral cavity or oropharynx treated with surgery with or without radiotherapy," Oral Oncology, vol. 35, no. 1, pp. 27-32, 1999.

[15] E. Hammerlid and C. Taft, "Health-related quality of life in long-term head and neck cancer survivors: a comparison with general population norms," British Journal of Cancer, vol. 84, no. 2, pp. 149-156, 2001.

[16] E. Hammerlid, E. Silander, L. Hörnestam et al., "Health-related quality of life three years after diagnosis of head and neck cancer-a longitudinal study," Head and Neck, vol. 23, no. 2, pp. 113-125, 2001.

[17] K. S. C. Chao, J. O. Deasy, J. Markman et al., "A prospective study of salivary function sparing in patients with head-and-neck cancers receiving intensity-modulated or three-dimensional radiation therapy: initial results," International Journal of Radiation Oncology. Biology. Physics, vol. 49, no. 4, pp. 907-916, 2001.

[18] M. Lambrecht, D. Nevens, and S. Nuyts, "Intensity-modulated radiotherapy versus parotid-sparing $3 \mathrm{D}$ conformal radiotherapy. Effect on outcome and toxicity in locally advanced head and neck cancer," Strahlentherapie und Onkologie, vol. 189, no. 3, pp. 223-229.

[19] "Comparative Effectiveness and Safety of Radiotherapy Treatments for Head and Neck Cancer," no. 29, US Department of Health and Human Services, Agency for Healthcare Research and Quality, 2007.

[20] M. R. Vergeer, P. A. H. Doornaert, D. H. F. Rietveld, C. R. Leemans, B. J. Slotman, and J. A. Langendijk, "Intensitymodulated radiotherapy reduces radiation-induced morbidity and improves health-related quality of life: results of a nonrandomized prospective study using a standardized follow-up program," International Journal of Radiation Oncology. Biology. Physics, vol. 74, no. 1, pp. 1-8, 2009.

[21] W.-C. Chen, T.-Z. Hwang, W.-H. Wang et al., "Comparison between conventional and intensity-modulated post-operative radiotherapy for stage III and IV oral cavity cancer in terms of treatment results and toxicity," Oral Oncology, vol. 45, no. 6, pp. 505-510, 2009.

[22] D. Rades, F. Fehlauer, J. Wroblesky, D. Albers, S. E. Schild, and R. Schmidt, "Prognostic factors in head-and-neck cancer patients treated with surgery followed by intensity-modulated radiotherapy (IMRT), 3D-conformal radiotherapy, or conventional radiotherapy," Oral Oncology, vol. 43, no. 6, pp. 535-543, 2007.

[23] T. Gupta, J. Agarwal, S. Jain et al., "Three-dimensional conformal radiotherapy (3D-CRT) versus intensity modulated radiation therapy (IMRT) in squamous cell carcinoma of the head and neck: a randomized controlled trial," Radiotherapy and Oncology, vol. 104, no. 3, pp. 343-348.

[24] G. Studer, U. M. Lütolf, and J. B. Davis, "IMRT in hypopharyngeal tumors," Strahlentherapie und Onkologie, vol. 182, no. 6, pp. 331-335, 2006.

[25] A. S. Garden, W. H. Morrison, P.-F. Wong et al., "Diseasecontrol rates following intensity-modulated radiation therapy for small primary oropharyngeal carcinoma," International Journal of Radiation Oncology. Biology. Physics, vol. 67, no. 2, pp. 438-444, 2007. 
[26] M. E. Daly, Q.-T. Le, P. G. Maxim et al., "Intensity-modulated radiotherapy in the treatment of oropharyngeal cancer: clinical outcomes and patterns of failure," International Journal of Radiation Oncology. Biology. Physics, vol. 76, no. 5, pp. 13391346, 2010.

[27] K. S. C. Chao, G. Ozyigit, A. I. Blanco et al., "Intensitymodulated radiation therapy for oropharyngeal carcinoma: impact of tumor volume," International Journal of Radiation Oncology. Biology. Physics, vol. 59, no. 1, pp. 43-50, 2004.

[28] K. Huang, P. Xia, C. Chuang et al., "Intensity-modulated chemoradiation for treatment of stage III and IV oropharyngeal carcinoma: the University of California-San Francisco experience," Cancer, vol. 113, no. 3, pp. 497-507, 2008.

[29] J. Setton, N. Caria, J. Romanyshyn et al., "Intensity-modulated radiotherapy in the treatment of oropharyngeal cancer: an update of the memorial sloan-kettering cancer center experience," International Journal of Radiation Oncology. Biology. Physics, vol. 82, no. 1, pp. 291-298, 2012.

[30] G. O. Schoenfeld, R. J. Amdur, C. G. Morris et al., "Patterns of failure and toxicity after intensity-modulated radiotherapy for head and neck cancer," International Journal of Radiation Oncology. Biology. Physics, vol. 71, no. 2, pp. 377-385, 2008.

[31] G. Sanguineti, G. B. Gunn, E. J. Endres, G. Chaljub, P. Cheruvu, and B. Parker, "Patterns of locoregional failure after exclusive IMRT for oropharyngeal carcinoma," International Journal of Radiation Oncology. Biology. Physics, vol. 72, no. 3, pp. 737-746, 2008.

[32] F. F. De Arruda, D. R. Puri, J. Zhung et al., "Intensitymodulated radiation therapy for the treatment of oropharyngeal carcinoma: the Memorial Sloan-Kettering Cancer Center experience," International Journal of Radiation Oncology. Biology. Physics, vol. 64, no. 2, pp. 363-373, 2006.

[33] F. C. S. Wong, A. W. Y. Ng, V. H. F. Lee et al., "Whole-field simultaneous integrated-boost intensity-modulated radiotherapy for patients with nasopharyngeal carcinoma," International Journal of Radiation Oncology. Biology. Physics, vol. 76, no. 1, pp. 138145, 2010.

[34] D. L. W. Kwong, E. H. N. Pow, J. S. T. Sham et al., "Intensitymodulated radiotherapy for early-stage nasopharyngeal carcinoma: a prospective study on disease control and preservation of salivary function," Cancer, vol. 101, no. 7, pp. 1584-1593, 2004.

[35] S. L. Wolden, W. C. Chen, D. G. Pfister, D. H. Kraus, S. L. Berry, and M. J. Zelefsky, "Intensity-modulated radiation therapy (IMRT) for nasopharynx cancer: update of the Memorial Sloan-Kettering experience," International Journal of Radiation Oncology. Biology. Physics, vol. 64, no. 1, pp. 57-62, 2006.

[36] M. K. M. Kam, P. M. L. Teo, R. M. C. Chau et al., "Treatment of nasopharyngeal carcinoma with intensity-modulated radiotherapy: the Hong Kong experience," International Journal of Radiation Oncology. Biology. Physics, vol. 60, no. 5, pp. 14401450, 2004.

[37] I. W. K. Tham, S. Lin, J. Pan, L. Han, J. J. Lu, and J. Wee, "Intensity-modulated radiation therapy without concurrent chemotherapy for stage IIB nasopharyngeal cancer," American Journal of Clinical Oncology, vol. 33, no. 3, pp. 294-299, 2010.

[38] N. Lee, J. Harris, A. S. Garden et al., "Intensity-modulated radiation therapy with or without chemotherapy for nasopharyngeal carcinoma: radiation therapy oncology group phase II trial 0225," Journal of Clinical Oncology, vol. 27, no. 22, pp. 36843690, 2009.

[39] I. W.-K. Tham, S. W. Hee, R. M.-C. Yeo et al., "Treatment of nasopharyngeal carcinoma using intensity-modulated radiotherapy-the national cancer centre singapore experience," International Journal of Radiation Oncology. Biology. Physics, vol. 75, no. 5, pp. 1481-1486, 2009.

[40] N. Lee, P. Xia, J. M. Quivey et al., "Intensity-modulated radiotherapy in the treatment of nasopharyngeal carcinoma: an update of the UCSF experience," International Journal of Radiation Oncology. Biology. Physics, vol. 53, no. 1, pp. 12-22, 2002.

[41] W.-S. Liu, M.-C. Su, M.-F. Wu, H.-C. Tseng, and H.-C. Kuo, "Nasopharyngeal carcinoma treated with precision-oriented radiation therapy techniques including intensity-modulated radiotherapy: preliminary results," Kaohsiung Journal of Medical Sciences, vol. 20, no. 2, pp. 49-55, 2004.

[42] W. Luo, L. Ye, Z. Yu, Z. He, F. Li, and M. Liu, "Effectiveness of three-dimensional conformal radiotherapy for treating early primary nasopharyngeal carcinoma," American Journal of Clinical Oncology, vol. 33, no. 6, pp. 604-608, 2010.

[43] R. Wang, F. Wu, H. Lu et al., "Definitive intensity-modulated radiation therapy for nasopharyngeal carcinoma: long-term outcome of a multicenter prospective study," Journal of Cancer Research and Clinical Oncology, vol. 139, no. 1, pp. 139-145, 2013.

[44] K. Sultanem, H.-K. Shu, P. Xia et al., "Three-dimensional intensity-modulated radiotherapy in the treatment of nasopharyngeal carcinoma: the University of California-San Francisco experience," International Journal of Radiation Oncology. Biology. Physics, vol. 48, no. 3, pp. 711-722, 2000.

[45] S.-F. Su, F. Han, C. Zhao et al., "Long-term outcomes of early-stage nasopharyngeal carcinoma patients treated with intensity-modulated radiotherapy alone," International Journal of Radiation Oncology. Biology. Physics, vol. 82, no. 1, pp. 327333, 2012.

[46] G. E. K. Gwi Eon Kim, J. Lim, H. C. P. Hee Chul Park et al., "A feasibility study using three-dimensional conformal boost technique in locally advanced carcinoma of the nasopharynx," Acta Oncologica, vol. 40, no. 5, pp. 582-587, 2001.

[47] A. Al-Mamgani, L. Tans, P. van Rooij, and P. C. Levendag, "A single-institutional experience of 15 years of treating T3 laryngeal cancer with primary radiotherapy, with or without chemotherapy," International Journal of Radiation Oncology, Biology, Physics, vol. 83, no. 3, pp. 1000-1006, 2012.

[48] G. Studer, R. A. Zwahlen, K. W. Graetz, B. J. Davis, and C. Glanzmann, "IMRT in oral cavity cancer," Radiation Oncology, vol. 2, no. 1, article 16, 2007.

[49] M. Yao, K. Chang, G. F. Funk et al., "The failure patterns of oral cavity squamous cell carcinoma after intensity-modulated radiotherapy-the university of iowa experience," International Journal of Radiation Oncology. Biology. Physics, vol. 67, no. 5, pp. 1332-1341, 2007.

[50] N. Y. Lee, W. O’Meara, K. Chan et al., "Concurrent chemotherapy and intensity-modulated radiotherapy for locoregionally advanced laryngeal and hypopharyngeal cancers," International Journal of Radiation Oncology. Biology. Physics, vol. 69, no. 2, pp. 459-468, 2007.

[51] D. Van Gestel, D. Van Den Weyngaert, D. Schrijvers, J. Weyler, and J. B. Vermorken, "Intensity-modulated radiotherapy in patients with head and neck cancer: a European single-centre experience," British Journal of Radiology, vol. 84, no. 1000, pp. 367-374, 2011.

[52] E. Peponi, C. Glanzmann, B. Willi, G. Huber, and G. Studer, "Dysphagia in head and neck cancer patients following intensity modulated radiotherapy (IMRT)," Radiation Oncology, vol. 6, no. 1, article 1, 2011. 
[53] I. Toledano, P. Graff, A. Serre et al., "Intensity-modulated radiotherapy in head and neck cancer: results of the prospective study GORTEC 2004-03," Radiotherapy and Oncology, vol. 103, no. 1, pp. 57-62, 2012.

[54] M. Yao, K. J. Dornfeld, J. M. Buatti et al., "Intensitymodulated radiation treatment for head-and-neck squamous cell carcinoma-the University of Iowa experience," International Journal of Radiation Oncology. Biology. Physics, vol. 63, no. 2, pp. 410-421, 2005.

[55] A. W. M. Lee, S. Y. Tung, A. T. C. Chan et al., "Preliminary results of a randomized study (NPC-9902 Trial) on therapeutic gain by concurrent chemotherapy and/or accelerated fractionation for locally advanced nasopharyngeal carcinoma," International Journal of Radiation Oncology. Biology. Physics, vol. 66, no. 1, pp. 142-151, 2006.

[56] A. W. M. Lee, W. H. Lau, S. Y. Tung et al., "Preliminary results of a randomized study on therapeutic gain by concurrent chemotherapy for regionally-advanced nasopharyngeal carcinoma: NPC-9901 trial by the Hong Kong Nasopharyngeal Cancer Study Group," Journal of Clinical Oncology, vol. 23, no. 28, pp. 6966-6975, 2005.

[57] M. Al-Sarraf, M. LeBlanc, P. G. S. Giri et al., "Chemoradiotherapy versus radiotherapy in patients with advanced nasopharyngeal cancer: phase III randomized Intergroup study 0099," Journal of Clinical Oncology, vol. 16, no. 4, pp. 1310-1317, 1998.

[58] B. Baujat, H. Audry, J. Bourhis et al., "Chemotherapy in locally advanced nasopharyngeal carcinoma: an individual patient data meta-analysis of eight randomised trials and 1753 patients," International Journal of Radiation Oncology. Biology. Physics, vol. 64, pp. 47-56, 2006.

[59] A. Vissink, F. R. Burlage, F. K. L. Spijkervet, J. Jansma, and R. P. Coppes, "Prevention and treatment of the consequences of head and neck radiotherapy," Critical Reviews in Oral Biology and Medicine, vol. 14, no. 3, pp. 213-225, 2003.

[60] A. Maes, C. Weltens, P. Flamen et al., "Preservation of parotid function with uncomplicated conformal radiotherapy," Radiotherapy and Oncology, vol. 63, no. 2, pp. 203-211, 2002.

[61] A. Eisbruch, H. M. Kim, J. E. Terrell, L. H. Marsh, L. A. Dawson, and J. A. Ship, "Xerostomia and its predictors following parotidsparing irradiation of head-and-neck cancer," International Journal of Radiation Oncology. Biology. Physics, vol. 50, no. 3, pp. 695-704, 2001.

[62] B. S. Henson, M. R. Inglehart, A. Eisbruch, and J. A. Ship, "Preserved salivary output and xerostomia-related quality of life in head and neck cancer patients receiving parotid-sparing radiotherapy," Oral Oncology, vol. 37, no. 1, pp. 84-93, 2001.

[63] M. W. Münter, C. P. Karger, S. G. Hoffner et al., "Evaluation of salivary gland function after treatment of head-and-neck tumors with intensity-modulated radiotherapy by quantitative pertechnetate scintigraphy," International Journal of Radiation Oncology. Biology. Physics, vol. 58, no. 1, pp. 175-184, 2004.

[64] A. I. Blanco, K. S. C. Chao, I. El Naqa et al., "Dose-volume modeling of salivary function in patients with head-andneck cancer receiving radiotherapy," International Journal of Radiation Oncology. Biology. Physics, vol. 62, no. 4, pp. 10551069, 2005.

[65] M. B. Parliament, R. A. Scrimger, S. G. Anderson et al., "Preservation of oral health-related quality of life and salivary flow rates after inverse-planned intensity-modulated radiotherapy (IMRT) for head-and-neck cancer," International Journal of Radiation Oncology. Biology. Physics, vol. 58, no. 3, pp. 663-673, 2004.
[66] A. P. Jellema, P. Doornaert, B. J. Slotman, C. Rene Leemans, and J. A. Langendijk, "Does radiation dose to the salivary glands and oral cavity predict patient-rated xerostomia and sticky saliva in head and neck cancer patients treated with curative radiotherapy?" Radiotherapy and Oncology, vol. 77, no. 2, pp. 164-171, 2005. 


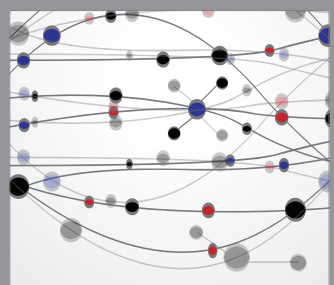

The Scientific World Journal
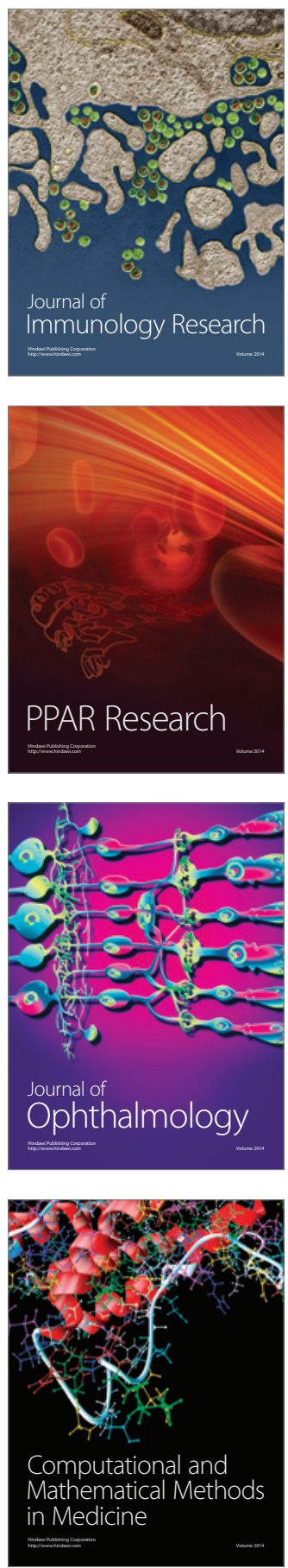

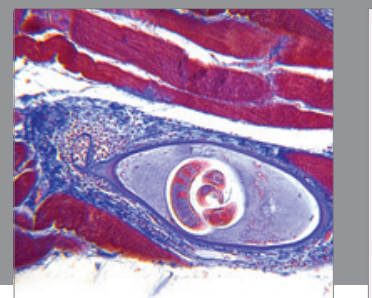

Gastroenterology

Research and Practice
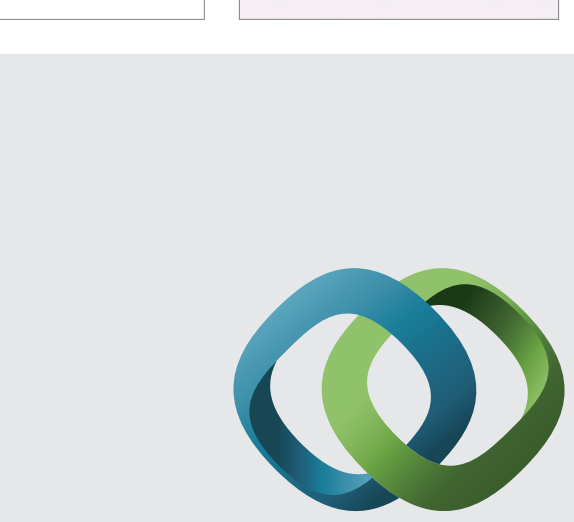

\section{Hindawi}

Submit your manuscripts at

http://www.hindawi.com
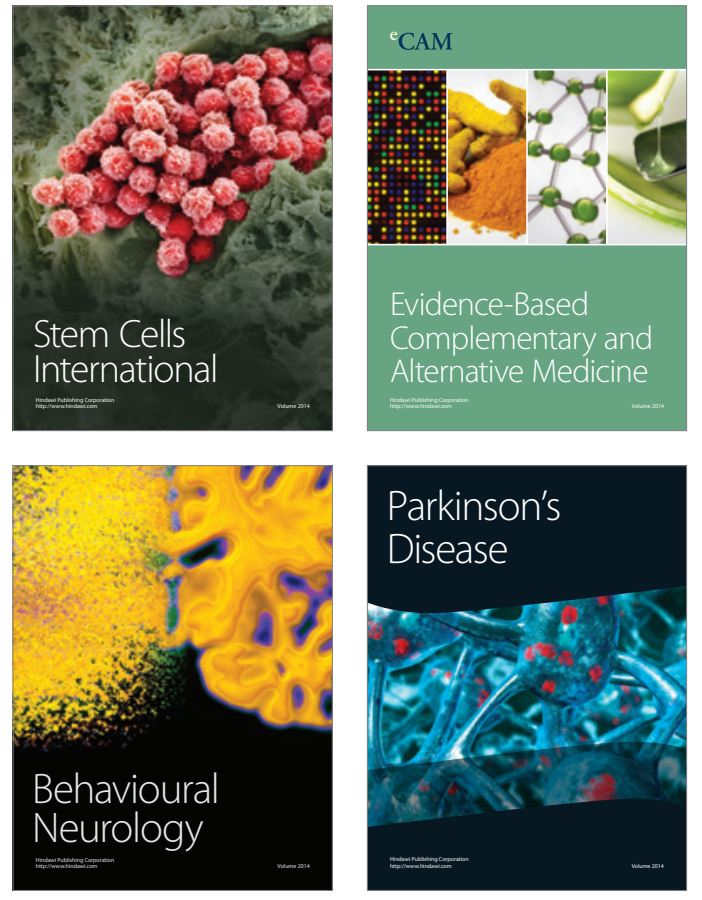
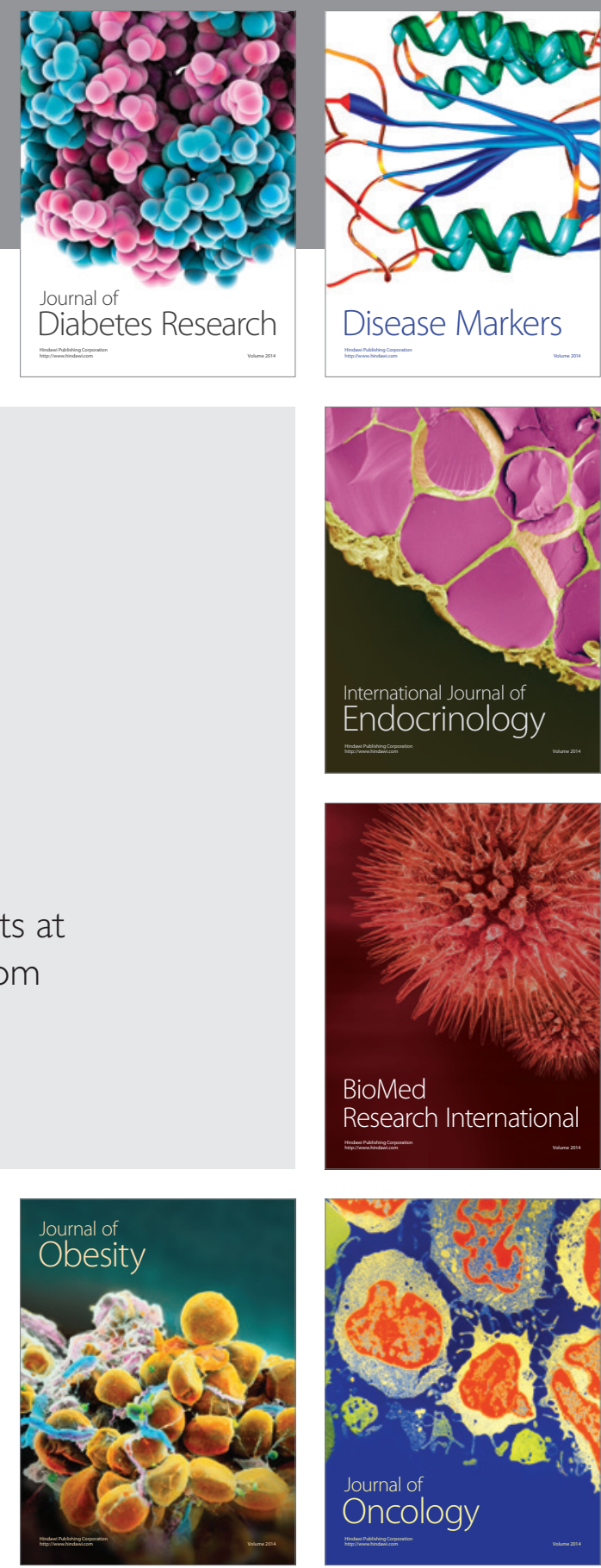

Disease Markers
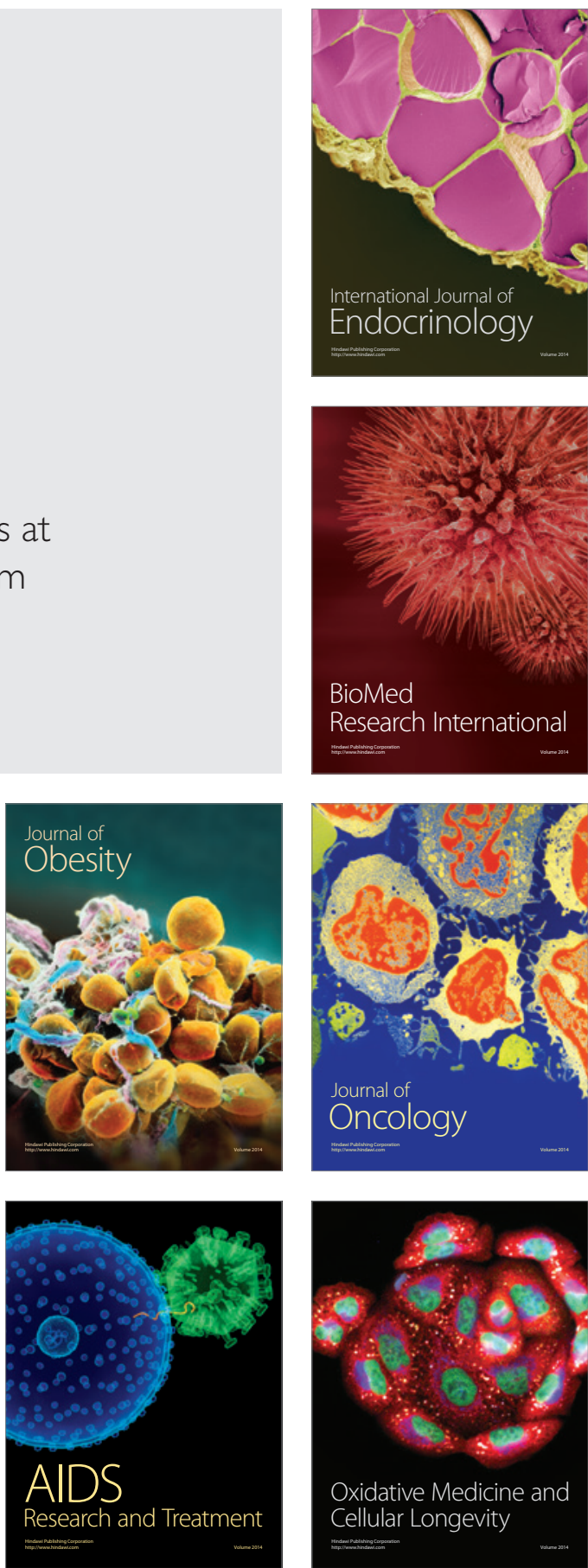